\title{
THE IMPACT OF TRACE ADDITIVES ON THE APPARENT SOLUBILITY OF HYDROGEN IN HEAVY OIL AND RELATED FEEDSTOCKS AT LOW AND HIGH TEMPERATURES
}

\section{Final Report}

Author: Jalal Abedi, Ph.D. (Principal Investigator)

Students: Jenine Breland (Undergraduate), Ivory Alexander (Undergraduate),

Okechukwu Nwachukwu (Undergraduate)

Address: Clark Atlanta University

223 James P. Brawley Dr., SW, Atlanta, GA 30314,

Phone: 404-880-6938

Fax: 404-880-6720

E-mail: jabedi@cau.edu

Grant No.: DE-FG26-01-NT41362

Performance Period:October 2001 to September 2002

September 2002 


\section{DISCLAIMER}

This report was prepared as an account of work sponsored by an agency of the United States government. Neither the United states Government nor any agency thereof, nor any of their employees, makes any warranty, express or implied, or assumes any legal liability or responsibility for the accuracy, completeness, or usefulness of any information, apparatus, product, or process disclosed, or represents that its use would not infringe privately owned rights. Reference herein to any specific commercial product, process, or service by trade name, trademark, manufacturer, or otherwise does not necessarily constitute or imply its endorsement, recommendation, or favoring by the United States Government or any agency thereof. The views and opinions of authors expressed herein do not necessarily state or reflect those of the United States Government or any agency thereof. 


\begin{abstract}
A systematic investigation was conducted to provide an accurate determination of hydrogen solubility in liquid media in temperatures in the range of $25^{-} 250^{\circ} \mathrm{C}$ and pressures in the range of $0.5-8 \mathrm{MPa}$. Results were obtained by an indirect gas solubility measurement method. The method was intended for use with high-resolution camera. The hydrogen solubility measurements were indirect and were based on pressure changes at constant temperature and measured volumes. Since the volume of the view cell was fixed the volume available for the vapor phase could be determined by measuring the location of the liquid-vapor interface. The interface was located to within the height of one pixel using high-resolution camera, which added $\pm 0.4 \mathrm{ml}$ to the uncertainty of the vapor volume. Liquid-liquid interface locations were measured with equal precision. The accuracy of the method was illustrated through hydrogen solubility measurements in hexadecane and tetralin, which were in close agreement with the values available in the literature. Hydrogen solubilities in Athabasca bitumen vacuum bottoms (ABVB) were reported over a broad range of temperatures $\left(80-250{ }^{\circ} \mathrm{C}\right)$ and pressures $(0.5-8 \mathrm{MPa})$.
\end{abstract}




\section{Table of Contents}

Abstract 3

Table of Contents $\quad 4$

List of Figures $\quad 5$

List of Tables

1.0 Introduction 5

1.1 Background 6

$\begin{array}{lll}1.2 & \text { Methodology } & 7\end{array}$

$\begin{array}{llr}2.0 & \text { Objectives } & 9\end{array}$

2.1 Overall Objectives 9

$\begin{array}{lll}2.2 \text { Specific Objectives } & 10\end{array}$

$\begin{array}{lr}\text { 3.0 Executive Summary } & 11\end{array}$

4.0 Approach and Accomplishments $\quad 12$

$\begin{array}{lll}4.1 & \text { Experimental } & 12\end{array}$

4.1.1 Apparatus 12

4.1.2 Procedure 14

4.2 Results and Discussion 15

4.2.1 Hydrogen solubility in organic solvent 14

4.2.2 Hydrogen solubility in ABVB 17

4.2.3 Sorption of hydrogen on solid surfaces in the presence of model liquid hydrocarbon 20

$\begin{array}{lll}4.3 & \text { Training } & 23\end{array}$

\begin{tabular}{ll}
5.0 & Conclusions and Future Work \\
\hline
\end{tabular}

$\begin{array}{lll}5.1 & \text { Conclusions } & 24\end{array}$

5.2 Improvement of the view cell apparatus 24

$\begin{array}{llr}\text { 6.0 } & \text { References } & 25\end{array}$ 


\section{List Of Figures}

Figure 1: Apparatus Schematic.

Figure 2: Vapor pressure measurements for ABVB.

Figure 3: Hydrogen Solubility in tetralin.

Figure 4: Hydrogen Solubility in tetralin.

Figure 5: Hydrogen Solubility in hexadecane.

Figure 6: Hydrogen Solubility in hexadecane.

Figure 7: Raw hydrogen solubility data for ABVB.

Figure 8: Hydrogen solubility coefficients for tetralin, hexadecane, and ABVB.

Figure 9: Hydrogen sorption kinetics at room temperature in the absence of solvent at a total pressure of $\sim 4.6 \mathrm{MPa}$, hydrogenation catalyst, and $\sim 6 \mathrm{MPa}$, for the activated carbon.

Figure 10: Apparent hydrogen solubilities in tetralin in the presence of alumina.

Figure 11: Apparent hydrogen solubility coefficient in tetralin in the presence of Alumina. 


\section{List Of Tables}

Table 1: Physical properties of model compounds and heavy oil

Table 2: Hydrogen solubility coefficients, moles of hydrogen/kg liquid/MPa 


\subsection{INTRODUCTION}

The solubility of hydrogen in liquid media is an important parameter required for the interpretation of rate data in gas-liquid, gas-liquid-liquid, and gas liquid-solid reactions. Hydrogen solubility and the trends for hydrogen solubility with increasing pressure and temperature are well known in pure hydrocarbon liquids as well as for simple and complex hydrocarbon mixtures - including bitumen. Systematic investigation began prior to the turn of the century and the pattern is well established. Hydrogen solubility starts from a low base and increases with temperature. High-pressure data are well fitted with a Henry's type constant, as the mass fraction of hydrogen in the liquid phase is low even at elevated pressures. While developing and subsequently updating a correlation for all such data applicable for ill-defined hydrocarbon fluids [1], we noted that some fluids did not follow the standard pattern. These included data from Grant Wilson [2] for three coal liquids and from IUPAC, 1981 for SRC-I another coal derived oil. More recently, we found that Gudao, a Chinese crude, also did not follow the standard pattern. Data for eight other coal liquids from diverse processes, as well as Athabasca bitumen followed the expected pattern, and their hydrogen solubilities were predicted within $10 \%$ over a broad range of conditions. In these five aberrant cases, a second pattern is evident. Hydrogen solubility is two to ten times higher than expected at low temperature, remains constant or increases slightly as temperature is increased then declines rapidly, at temperatures above $625 \mathrm{~K}$ (where data are available). We found this behavior puzzling initially but now surmise that the sorption phenomena has merely swamped homogeneous dissolution [3]. Whether the sorption is physical or chemical in nature, it would readily account for the apparently aberrant experimental observations and this was the starting point of the research reported here. The nature of the surfaces present in the aberrant cases is unknown. In this work, the impact of solid additives (alumina and carbon black) on the apparent solubility of hydrogen in hexadecane and tetralin were assessed over a wide range of conditions in order to obtain an explanation for this phenomenon. 


\subsection{Background}

Hydrogen is a key reagent in upgrading processes for heavy oil [4]. Unfortunately, it has a very low solubility in these feedstocks. Typical values range from 0.001 moles of hydrogen $/ \mathrm{kg}$ of liquid/ $100 \mathrm{kPa}$ at room temperature to 0.01 moles of hydrogen $/ \mathrm{kg}$ of liquid/ $100 \mathrm{kPa}$ under processing conditions [5]. Consequently, upgrading processes for these feedstocks operate at elevated pressures and temperatures. Recent published and unpublished work suggests that apparent hydrogen solubilities can exist greatly in excess of these values, particularly at low temperatures [6]. We attribute such differences to the presence of catalyst or other surfaces in the fluid. During this study we plan to examine the impact of additives on the apparent solubility of hydrogen in fluids associated with such processes at room and elevated temperatures and pressures. This issue has yet to be explored quantitatively in the open literature. We anticipate that by increasing the amount of hydrogen available in the "liquid" phase (i.e.: by keeping the liquid saturated with hydrogen, through the release of sorbed hydrogen), the reaction kinetics will be improved [7], and hydrogen will be used more efficiently (currently, large volumes of hydrogen are recycled through hydrogenation / hydrogenolysis reactors). In a related study we plan to explore whether this is just another role for "catalysts" or whether in fact it is the principal role for "catalysts" in these systems. The possible benefits to processors are significant, as it may prove in the longer term that any material which enhances hydrogen solubility, from red mud to carbon black to more expensive catalysts, might work equally effectively, if equivalent "surface areas" and desorption behavior are employed. For the case of hydrogen sorption on palladium and nickel [3], the Ni and Pd surfaces saturate at $\sim 0.6$ atoms of hydrogen/atom of $\mathrm{Pd}$ or $\mathrm{Ni}$. At room temperature this occurs at $\sim 1 \mathrm{kPa}$, at $300 \mathrm{C} \sim 1 \mathrm{MPa}$, at $400 \mathrm{C} \sim 10 \mathrm{MPa}$. If we were to operate a process at $\sim 6 \mathrm{MPa}$ using this catalyst we should see a sharp decrease in sorbed hydrogen in the $350 \mathrm{C}$ range. Other catalysts or surfaces would show similar decreases under other conditions. Thus the operating pressure for processes with different catalysts may be dictated by the temperature range over which a catalyst desorbs hydrogen at a given pressure rather than by reaction kinetics per se. 


\subsection{Methodology}

There are several experimental methods for the measurement of hydrogen solubility in liquids. The most commonly used techniques can be grouped as direct and indirect methods. In typical direct measurement methods [8-11], a known amount of liquid at equilibrium is sampled and hydrogen solubility is measured using gas chromatography. In indirect methods $[12,13]$, hydrogen solubilities are calculated from the pressure drop in a hydrogen loading tank of known volume and temperature, and the pressure increases in the view cell once equilibrium is established. Other methods calculate hydrogen solubility from direct measurements of hydrogen partial pressures $[14,15]$. In general, direct methods are believed to be more accurate. However, sampling does create uncertainties and it does render the measurements tedious. By contrast, the indirect methods do not involve sampling and measurements can often be carried out at high temperatures and pressures. They are more convenient and especially well suited for prompt generation of solubility data in liquids under extreme conditions.

Apparent hydrogen solubility and sorbed hydrogen measurements are both made indirectly using a $201 \mathrm{ml}$ view-cell equipped with a sapphire window. Liquid and vapor volumes are measured to $+/-0.1 \mathrm{ml}$ at temperatures and pressures of interest using a highmagnification video data-acquisition-system. A known number of moles of hydrogen are added to the cell. The number of moles of hydrogen in the gas phase is determined using the equation of state (based on pressure, temperature and volume measurements). The amount of hydrogen in the "liquid" phase is determined by difference. Sorption isotherms are then constructed by subtracting the number of moles dissolved homogeneously (experiments are also conducted in the absence of additives) from the number of moles present in the "liquid" phase. These sorption isotherms will provide insights into the nature of the sorption phenomenon in each case, as well as sorption capacity of the additives as outlined in standard reference texts [16]. Specific additives include carbon black and alumina. As we did not plan to sample the gas phase, the view cell is operated at or below the normal boiling point of the liquids employed, at pressures in the range of 1 to $8 \mathrm{MPa}$. The impact of mass balance errors on apparent solubility 
measurements are further minimized by operating the view cell approximately half full with liquid.

During a typical experiment, a known mass of additive and "liquid" (+/- $0.02 \mathrm{~g})$ is placed in the view cell. The cell is then placed under a mild vacuum ( $2 \mathrm{kPa}$ ) to remove air from the vapor space. The view cell is then agitated and reconnected to the vacuum line to remove dissolved air. Then the line connecting the hydrogen gas cylinder to the view cell via a 0.300 -liter hydrogen feed tank is evacuated and flushed with hydrogen. The pressure in the hydrogen feed tank is then raised to the pressure of the hydrogen cylinder, the feed tank is then isolated and the pressure is measured with a pressure transducer $(+/-$ $0.1 \%$ full scale). The line connecting the feed tank to the view cell is then opened and a second pressure reading is taken. The view cell is then isolated and allowed to reach equilibrium at room temperature, at which time a third pressure reading is taken. The cell can then be heated and allowed to equilibrate at other temperatures. Once cooled to room temperature again additional allocates of hydrogen can be added to the cell and the subsequent steps repeated. In this manner, a range of apparent solubility data and consequently a series of sorption isotherms can be generated in an efficient manner. For most experiments the additive mass is set at 1 mass $\%$ of the solvent. 


\subsection{OBJECTIVES}

\subsection{Overall Objectives}

The primary focus of this work is to develop an interdisciplinary phase equilibrium thermodynamics education and research program. The two development areas forming the program are described: (1) education and (2) research. The long-term research directions outlined in area (2) specify a research agenda designed to sustain and nurture the program's growth. The research plan allows us to develop and enhance the quality of our research program. Specifically, it would greatly strengthen our research capabilities in areas related to phase equilibrium thermodynamics by developing a thermodynamics experimental facilities and providing state of the art experimental instrumentation for multiphase behavior of complex systems. The thermodynamics facilities would enable students to participate in the experimental study of heavy fluid systems and also to understand the fundamental underlying processes. Thus, the project improves and upgrades the existing facilities and capabilities and strengthens the University's thermodynamics research infrastructure significantly. Specifically, it has the following impact on science and engineering students:

- Better understanding of the practical applications of the mathematical tools and concepts learned,

- Enhanced understanding of the importance of physical phenomena (interfaces, phase equilibrium) in the design and operation of multiphase reactors,

- Appreciation of the issues that arise in progressing from a lab, through a pilot, and to an industrial scale of the separation processes they undertake in the lab,

- Enhanced knowledge in phase behavior of heavy fluid mixtures, heavy oil upgrading, and data acquisition and analysis,

- Acquisition of better training and knowledge in separation processes and thermal science (thermodynamics, heat and mass transfer, and fluid mechanics). 


\subsection{Specific Objectives}

TASK 1: Develop thermodynamics experimental facilities to enhance the quality of CAU's science and engineering program, especially for the engineering students in the chemical and mechanical engineering programs.

TASK 2: Educate graduate and undergraduate students at CAU through research as well as contact with the industry. Such exchange will bring together students and scientist in industry and introduce students to future career opportunities. I will use this project to train students in a variety of areas, including high temperatures and high pressures processes, thermodynamics, physical chemistry, mass transfer, and phase equilibrium. The students will participate in developing the experimental facility, conducting experiment and analysis, and other research activities together with CAU faculty and engineers.

TASK3: Specific data collection

- Verify the accuracy of the proposed indirect hydrogen solubility measurement method by duplicating some accurate $(+/-1 \%)$ solubility data reported in the literature,

- Confirm the unusually high hydrogen solubility measurements for Athabasca bitumen + catalyst at room temperature,

- Determine the relative impact of additives such as carbon black, spent catalyst (metallic sulfides, "coke"), fresh catalyst (metallic oxides), porphyrins, asphaltenes on the apparent solubility of hydrogen in model feedstocks (neicosane, $T_{b}=617 \mathrm{~K}$; phenanthrene, $T_{b}=613 \mathrm{~K}$ ) over a range of temperatures and pressures.

TASK 4: Despite the fact that heavy oil upgrading processes are successful commercially, many aspects of the reaction environment are unclear. Issues such as the number of phases present, and the impact of phase behavior on reaction kinetics are only now being resolved quantitatively (Abedi et al, 1998). The roles played by hydrogen and even 
catalysts in these processes are also debated. This study will provide fundamental data concerning the nature of the reaction environment associated with heavy oil/bitumen upgrading processes and it is hoped that these data will facilitate the development of optimum process/reactor designs, and improve the operation of existing processes (Economic and Technological Advantages).

TASK 5: Communicate results of research. Present the results in various conferences and meetings. 


\subsection{EXECUTIVE SUMMRY}

A systematic investigation was conducted to provide an accurate determination of hydrogen solubility in liquid media in temperatures in the range of $25^{-} 250^{\circ} \mathrm{C}$ and pressures in the range of $0.5-8 \mathrm{MPa}$. Results were obtained by an indirect gas solubility measurement method. The method was intended for use with high-resolution camera. The hydrogen solubility measurements were based on pressure changes at constant temperature and measured volumes. Since the volume of the view cell was fixed, the volume for the vapor phase could be determined by measuring the location of the liquidvapor interface. The interface height was determined with an accuracy one pixel using a high-resolution camera. This added $\pm 0.4 \mathrm{ml}$ to the uncertainty of the vapor volume. Liquid-liquid interface locations were measured with equal precision. The accuracy of the method was illustrated through hydrogen solubility measurements in hexadecane and tetralin. The results were in close agreement with the values available in the literature. Hydrogen solubilities in ABVB were reported over a broad range of temperatures (80$\left.250{ }^{\circ} \mathrm{C}\right)$ and pressures $(0.5-8 \mathrm{MPa})$.

Hydrogen solubility measurements were indirect and based on pressure changes at constant temperature and measured volumes. Thus, it was very important to maximize the accuracy of each measurement and minimize the amount of uncertainties. Six blank experiments comprising of only hydrogen, conducted at temperatures up to $250{ }^{\circ} \mathrm{C}$ and 8 MPa showed that the error threshold for solubility measurements was less than \pm 0.0005 mol. Given the range of hydrogen solubilities in hydrocarbon fluids, such an error limits the application of the experimental method to high pressures. The overall error of the method was assessed by comparing solubility data obtained using this method for tetralin with reliable high pressure data reported previously for the same system. The error associated with latter data was generally less than $\pm 0.1 \%$. The differences between the two sets of measurements were less than $\pm 0.5 \%$ for pressures greater than $4 \mathrm{MPa}$. A second set of comparisons was performed for hydrogen solubility in hexadecane. Again the differences between the two sets of measurements were less than $5 \%$. We conclude that, the proposed method for solubility measurement is accurate and reliable over a broad range of temperatures at pressures where gas solubility is substantially greater than the threshold $\sim 0.0005 \mathrm{~mol}$.

In the case of $\mathrm{ABVB}$, the measurements ranged from 0.55 to $8 \mathrm{MPa}$ and were set at 130 ${ }^{\circ} \mathrm{C}$ and $186{ }^{\circ} \mathrm{C}$. Because of the high viscosity of ABVB at low temperatures, hydrogen solubility in ABVB was measured at temperatures as low as $130{ }^{\circ} \mathrm{C}$. ABVB chemical reactions usually occurred at temperatures above $250{ }^{\circ} \mathrm{C}$. Since our system was operating under $186{ }^{\circ} \mathrm{C}$, the reaction was not an issue. Hydrogen solubilities varied linearly with pressure at constant temperature within experimental error. Thus, a Henry-like coefficient for hydrogen solubility with the units moles of hydrogen $/ \mathrm{kg}$ of liquid $/ 100 \mathrm{kPa}$ was derived from each set of data by fitting straight lines to the solubility data which pass through the origin. These coefficients allowed us to extrapolate the high-pressure solubility database to the low pressures for which accurate measurements were not possible. ABVB exhibited a sharp increase in hydrogen solubility with temperature. For example, the ratio of hydrogen solubility in tetralin to hydrogen solubility in ABVB at 
$130{ }^{\circ} \mathrm{C}$ was $\sim 1.7: 1$. This ratio decreased to $\sim 1.3: 1$ at $186{ }^{\circ} \mathrm{C}$. One would not anticipate that the values for hydrogen solubility in heavy fluids would converge with those in lighter fluids, as temperature is increased and co-relations from hydrogen solubilities measured under low temperature conditions do not anticipate such a convergence.

Hydrogen sorption rates on activated carbon, even in the absence of solvent, are too low to affect measured hydrogen solubility values for liquids. However, a commercial alumina supported hydrogenation catalyst, did sorb quickly enough to affect apparent solubility measurements within that time frame. For example, after 1 hour at $4.6 \mathrm{MPa}$, the catalyst sorbed as much hydrogen per $\mathrm{kg}$ as was soluble in toluene at the same pressure $\sim 0.15$ moles $/ \mathrm{kg}$. Based on its BET surface area, $280 \mathrm{~m}^{2} / \mathrm{g}$, and assuming that the surface area occupied per sorbed molecule was $15 \times 10^{-20} \mathrm{~m}^{2}$, the ultimate sorbative capacity of the catalyst was $\sim 3.3$ moles of hydrogen $/ \mathrm{kg}$ of catalyst - as long as the pressure is above a threshold value. Therefore at longer exposure times and at lower total pressures surface sorption can play a dominant role in apparent solubility measurement, even for low molar mass solvents. Since hydrogen solubility in heavy oils is much lower than in toluene at low temperature, excessive apparent solubilities are clearly possible.

We obtained apparent hydrogen solubility measurements in tetralin in the presence of an additive. The apparent hydrogen solubilities were reported on the basis of liquid mass for ease of comparison with intrinsic hydrogen solubilities in tetralin. Hydrogen did not sorb significantly on alumina surface in the presence of tetralin despite its high sorption capacity for hydrogen in the absence of these model hydrocarbons. In this case liquid suppresses hydrogen sorption on the solids, i.e.: liquid was sorbed preferentially. We are planning a follow up study to examine the impact of natural clay, asphaltenes, silica, and commercial hydrotreating catalyst on the apparent solubility of hydrogen in hydrocarbon fluids. 


\subsection{APPROACH AND ACCOMPLISHMENTS}

\subsection{EXPERIMENTAL}

\subsubsection{Apparatus}

A schematic of the apparatus as configured for solubility measurement is given in Figure

1. The apparatus consisted of a view cell and a gas-loading reservoir. The cylindrical view cell was made of transparent glass. The view cell was able to withstand a broad range of operating conditions: pressure from vacuum to $8 \mathrm{MPa}$ and temperature up to 300 ${ }^{\circ} \mathrm{C}$. Approximately $100 \mathrm{ml}$ of liquid was loaded into the cell at the beginning of each experiment using a syringe. Gas could be added continually during an experiment from the gas-loading reservoir, which was operated at a controlled and constant temperature 30 $\pm 0.1{ }^{\circ} \mathrm{C}$. Pressure in the view cell and gas-loading reservoir were monitored using two pressure transducers. The combined uncertainty of the transducer and pressure readout was $\pm 2 \mathrm{kPa}$. View cell temperature was controlled to within $\pm 1{ }^{\circ} \mathrm{C}$. The volumes of the gas-loading reservoir and view cell were measured using the water replacement method and are $372.0 \pm 0.2$ and $201 . \pm 0.8 \mathrm{ml}$, respectively.

\subsubsection{Procedure}

For a typical hydrogen solubility experiment, the view cell was heated under vacuum to $100{ }^{\circ} \mathrm{C}$ for 20 minutes to release surface moisture. Then, it was allowed to cool to room temperature under vacuum before a known amount of a liquid was drawn into the view cell. The liquid was then degassed at its bubble pressure or $10 \mathrm{kPa}$ at ambient temperature for $20 \mathrm{~min}$. Afterward, the view cell was heated to a target temperature with its pressure monitored and taken as a reference datum for the vapor pressure of the liquid. Vapor pressures of liquid can be measured conveniently by this method. For example, vapor pressure measurements for hexadecane measured in this manner were in good agreement with values reported elsewhere at temperatures above $200{ }^{\circ} \mathrm{C}$. At low temperatures, vapor pressures of heavy hydrocarbon were negligible compared with hydrogen partial pressures employed as shown in Figure 2. 


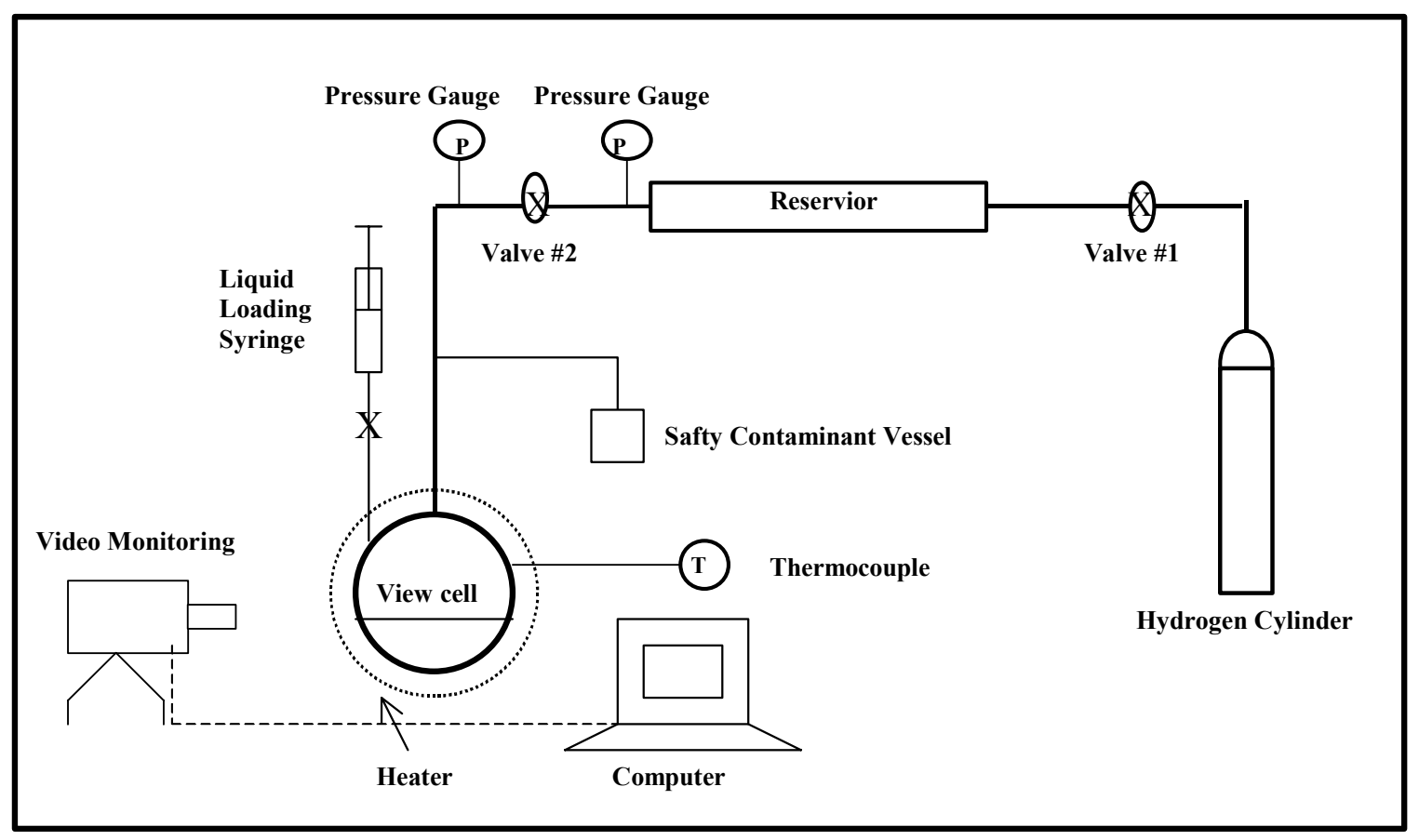

Figure 1: Apparatus Schematic.

To begin hydrogen solubility measurements measurements, the gas-loading reservoir was charged with high-pressure hydrogen from a gas cylinder by opening valve \#1. Hydrogen was then allowed to reach thermal equilibrium in the gas-loading reservoir ( $\sim \mathrm{min})$. Hydrogen was discharged from the loading reservoir to the view cell by opening valve 2 (Figure 1). After 1 min valve \#2 is shut and both the view cell and the gas reservoir were allowed to reach equilibrium $(\sim 5 \mathrm{~min})$. The number of moles of hydrogen released from the loading reservoir and present in the vapor phase in the view cell were determined from the generalized equation of state, Equation (1):

$n=\frac{P V}{Z R T}$

Where $\mathrm{Z}=\mathrm{F}(\mathrm{T}, \mathrm{P})$, determine from the generalized compressibility chart, using modified critical constants for hydrogen[17]. More complex equations of state were not necessary 
as $\mathrm{Z}$ was approximately unity. The amount of hydrogen dissolved in the liquid, $\mathrm{n}_{\mathrm{H}}$, was obtained by the difference from the pressure, temperature, and volume measurements:

$n_{H 2}^{L}=\frac{V_{R}}{R T_{R}}\left(P_{R}^{i}-P_{R}^{f}\right)-\frac{V_{\text {cell }}-V_{l}}{R T_{\text {cell }}}\left(P_{\text {cell }}^{f}-P_{\text {liq }}^{*}\right)$

Where $\mathrm{P}^{*}$ is the vapor pressure of the solvent and the other terms possess standard definitions. The amounts of hydrogen sorbed by the solid, $n_{H 2}^{S}$, and by the liquid + solid mixture, $n_{H 2}^{S+L}$, were obtained in an analogous manner in equations (3) and (4):

$n_{H 2}^{S}=\frac{V_{R}}{R T_{R}}\left(P_{R}^{i}-P_{R}^{f}\right)-\frac{P_{\text {cell }}^{f}\left(V_{\text {cell }}-V_{l}\right)}{R T_{\text {cell }}}$

$n_{H 2}^{S+L}=\frac{V_{R}}{R T_{R}}\left(P_{R}^{i}-P_{R}^{f}\right)-\frac{V_{\text {cell }}-V_{l}-V_{\text {solid }}}{R T_{\text {cell }}}\left(P_{\text {cell }}^{f}-P_{\text {liq }}^{*}\right)$

Clearly, the value obtained for the number of moles of hydrogen is sensitive to the location of the liquid-vapor interface. During a typical experiment, black and white images from the CCD camera were displayed and recorded on videotape. A frame grabber enabled us to record images digitally for further image analysis. The location of the interface and hence the gas volume was obtained accurately from the images.

Hydrogen addition was repeated using approximately $2 \mathrm{MPa}$ increments up to pressures of about $8 \mathrm{MPa}$, the maximum attainable pressure in the view cell. Dividing by the mass of solvent normalized these raw solubility measurements, allowing us to plot hydrogen solubility versus hydrogen partial pressure. At temperatures where the vapor pressure of the liquid was negligible, the reverse process with decreasing pressure could be carried out to determine whether a leak has occurred. It should also be noted that at each experimental conditions the phase behavior of the hydrocarbon + hydrogen mixtures and adequacy of mixing were assessed. Liquid-vapor phase behavior was observed in all cases. The temperatures of $\sim 80^{\circ} \mathrm{C}$ and above the viscosity of the ABVB and heavy oil 
fractions, with the exception of ABVBs was low enough to ensure adequate mixing and phase disengagement.

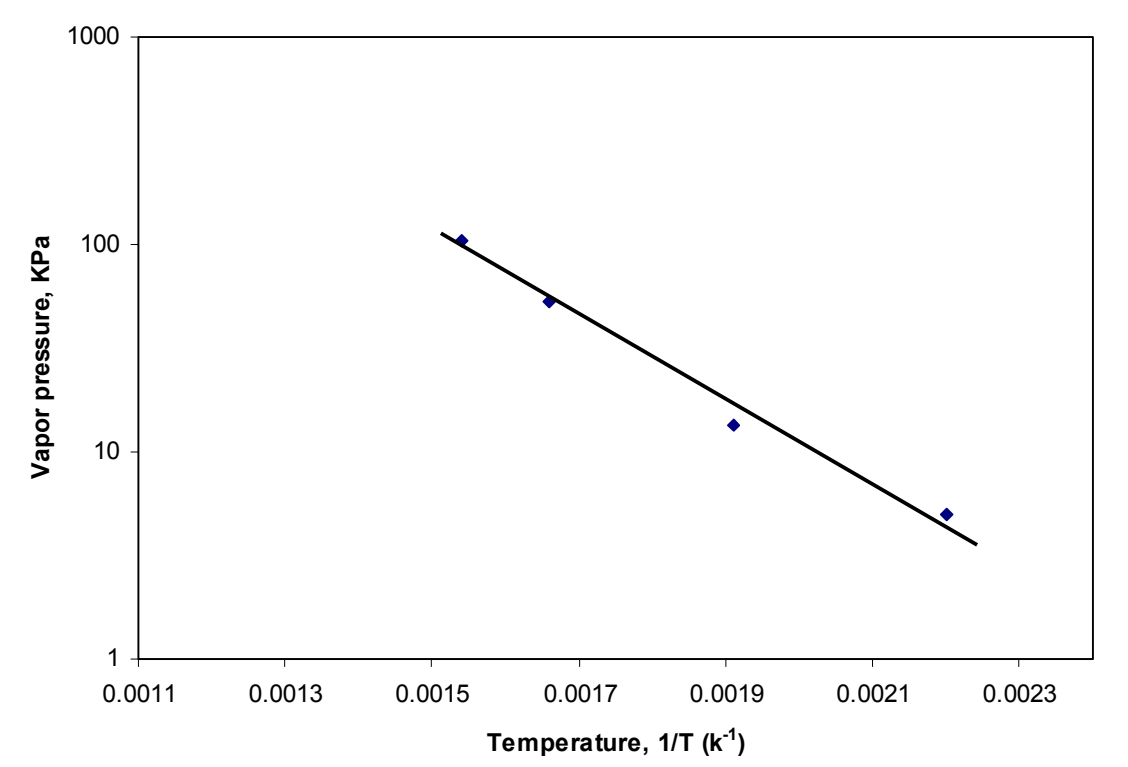

Figure 2: Vapor pressure measurements for ABVB.

\subsection{RESULTS AND DISCUSSION}

\subsubsection{Hydrogen solubility in organic solvent}

Since the hydrogen solubility measurements were indirect, i.e. they were based on pressure changes at constant temperature and measured volumes, it was very important that every measurement was as accurate as possible, and that uncertainties were as small as possible. The volume of the view cell $(201 \mathrm{ml} \pm 0.8)$ is fixed. Thus the volume available for the vapor phase could be determined by measuring the location of the liquid-vapor interface. The interface could be located to within the height of one pixel using images, which added $\pm 0.4 \mathrm{ml}$ to the uncertainty of the vapor volume. Liquid-liquid interface locations, if present, could also be measured with equal precision. Further, six blank experiments comprising of only hydrogen, conducted at temperatures up to $250{ }^{\circ} \mathrm{C}$ and $8 \mathrm{MPa}$ showed that the error threshold for solubility measurements is less than \pm 
$0.0005 \mathrm{~mol}$. However, given the range of hydrogen solubilities in hydrocarbon fluids, this limited the application of the experimental method to high pressures. The overall error of the method was assessed by comparing solubility data obtained using this method for tetralin with reliable high pressure data reported previously for the same system [18-19]. The error associated with these latter data was generally considered to be less than \pm $0.1 \%$. The isobars shown in Figures 3 and 4, illustrate the close agreement between the two sets of data. The differences between the two sets of measurements were less than \pm $0.5 \%$, particularly at pressures exceeding $4 \mathrm{MPa}$. A second set of comparisons is shown in Figures 5 and 6 for hydrogen solubility in hexadecane. Again the agreement between the two sets of measurements falls within $5 \%$. We conclude that, the proposed method for solubility measurement is accurate and reliable over a broad range of temperatures at pressures where gas solubility is substantially greater than the threshold $\sim 0.0005 \mathrm{~mol}$.

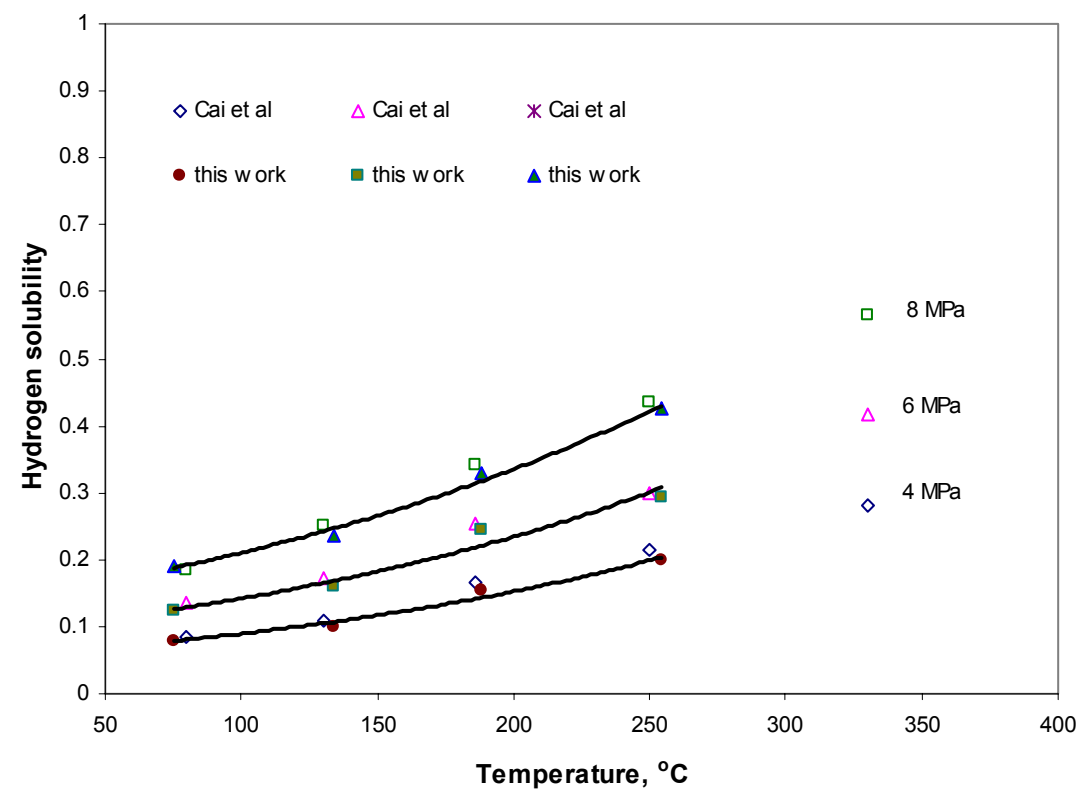

Figure 3: Hydrogen Solubility in tetralin 


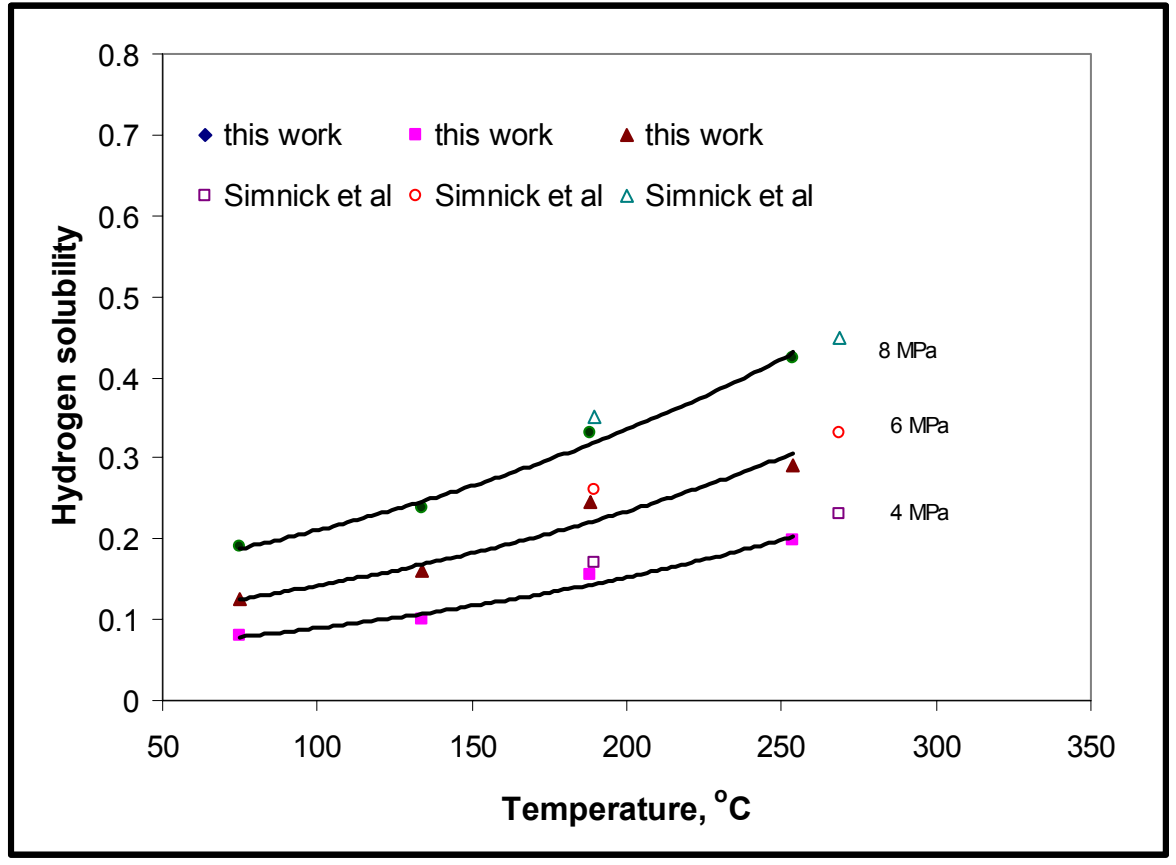

Figure 4: Hydrogen Solubility in tetralin

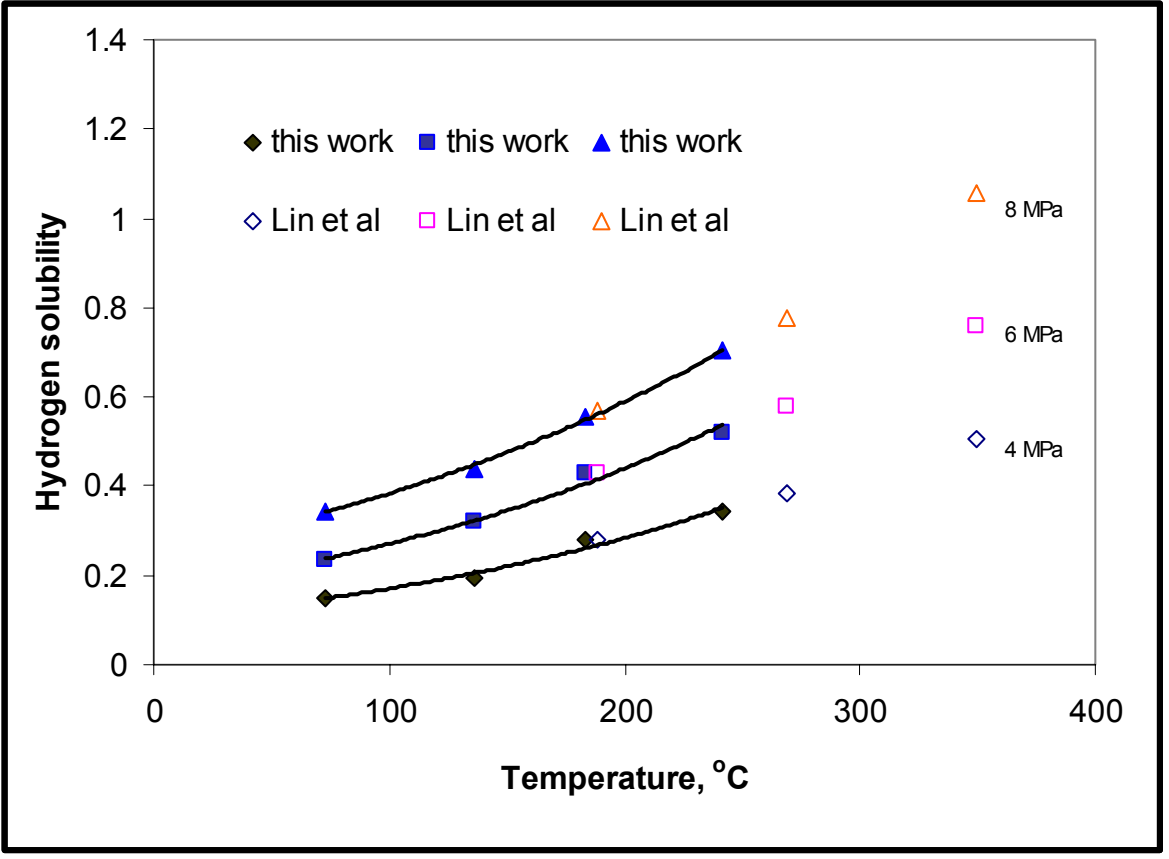

Figure 5: Hydrogen Solubility in hexadecane 


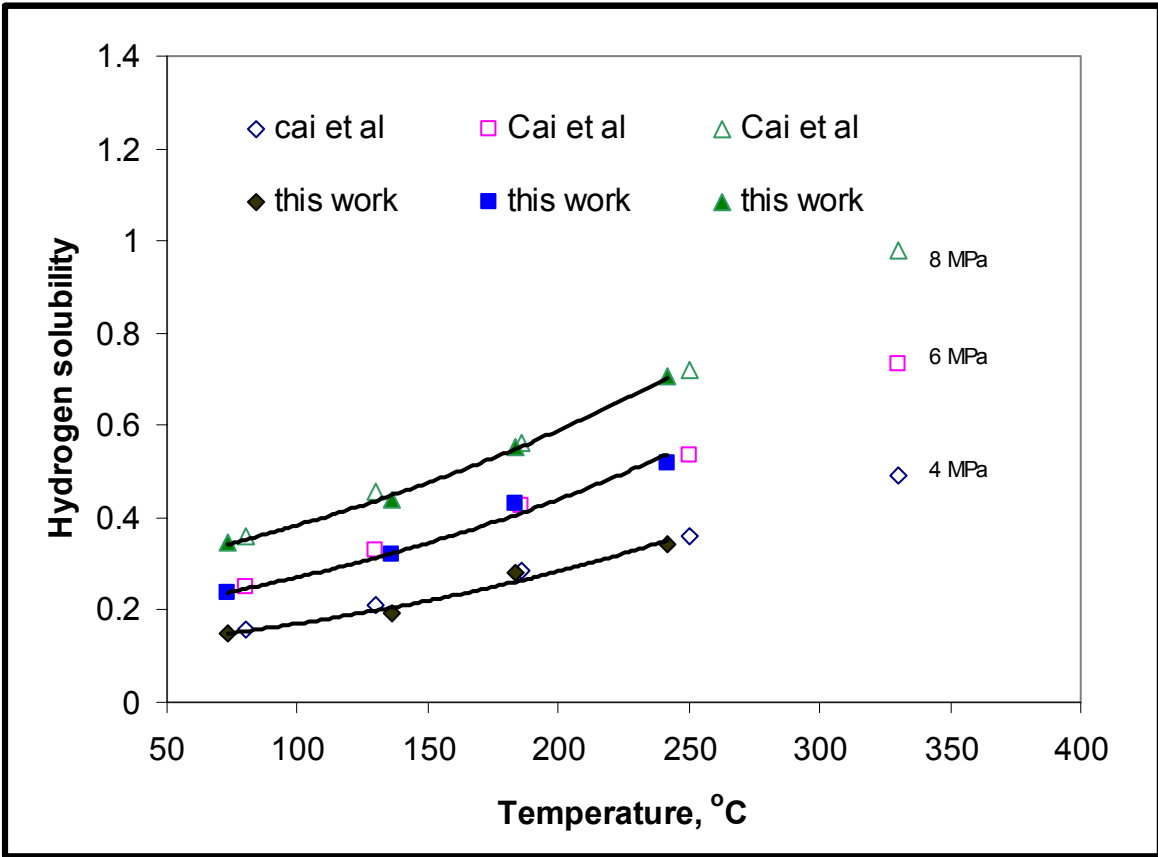

Figure 6: Hydrogen Solubility in hexadecane

\subsubsection{Hydrogen solubility in Athabsca ABVB vacuum bottom}

Hydrogen solubility in ABVB was measured. The physical properties are given in Table 1 and solubility measurements obtained for the samples is shown in Figure 7. The measurements ranged from 0.55 to $8 \mathrm{MPa}$ and were set at $130{ }^{\circ} \mathrm{C}$ and $186{ }^{\circ} \mathrm{C}$. Because of the high viscosity of ABVB at low temperatures, hydrogen solubility in ABVB was measured at temperature as low as $130{ }^{\circ} \mathrm{C}$. Each of the isotherms shown in Figure 7 was obtained from an individual experiment. At the end of each experiment during the holding period, where no additional hydrogen was admitted into the view cell, pressure were measured every $5 \mathrm{~min}$ for $20-35 \mathrm{~min}$ to check for leaks or chemical reaction. The declining view cell pressure (continuously increasing apparent hydrogen solubility) indicated a non-equilibrium state caused by either chemical reaction or leaks. When such a phenomenon was observed, an extensive leakage test was carried out after the system was cooled to near ambient temperature. All such tests revealed leakage problems and the 
dynamic state was not attributed to chemical reaction. For ABVB chemical reactions usually occured at temperatures above $250{ }^{\circ} \mathrm{C}$. Since our system was operating under 186 ${ }^{\circ} \mathrm{C}$, the reaction was not an issue. Hydrogen solubilities reported in Figure 7 varied linearly with pressure at constant temperature within experimental error. Thus, a Henrylike coefficient for hydrogen solubility with the units moles of hydrogen/kg of liquid/100 $\mathrm{kPa}$ was derived from each set of data by fitting straight lines to the solubility data which passed through the origin. These coefficients allowed us to extrapolate the high pressure solubility data base to the low pressures for which accurate measurements were not possible.

Table 1: Physical properties of model compounds and heavy oil

\begin{tabular}{|l|c|c|c|}
\hline & Tetralin & Hexadecane & ABVB \\
\hline $\mathrm{C}(\mathrm{wt} \%)$ & 90.9 & 84.8 & 84.3 \\
\hline $\mathrm{H}(\mathrm{wt} \%)$ & 9.1 & 15.2 & 10.9 \\
\hline $\mathrm{N}(\mathrm{wt} \%)$ & 0 & 0 & 0.8 \\
\hline $\mathrm{S}(\mathrm{wt} \%)$ & 0 & 0 & 3.5 \\
\hline Density at $20^{\circ} \mathrm{C}$ & 0.966 & 0.773 & 1.05 \\
\hline Mean molar mass & 132 & 236 & 1700 \\
\hline Aromatic carbon $(\%)$ & 60 & 0 & 35 \\
\hline $\mathrm{H} / \mathrm{C}$ ratio & 1.20 & 2.13 & 1.52 \\
\hline
\end{tabular}

Hydrogen solubility coefficients for hexadecane, tetralin, and ABVB that are derived from the data reported above are presented in Figure 8 and Table 2. As shown in Figure 8 , ABVB exhibited a sharp increase in hydrogen solubility with temperature. For example, the ratio of hydrogen solubility in tetralin to hydrogen solubility in ABVB at $130{ }^{\circ} \mathrm{C}$ was $\sim 1.7: 1$. This ratio decreased to $\sim 1.3: 1$ at $186{ }^{\circ} \mathrm{C}$. One would not anticipate that the values for hydrogen solubility in heavy fluids would converge with those in lighter fluids as temperature is increased, and co-relations from hydrogen solubilities measured under low temperature conditions do not anticipate such a convergence. 


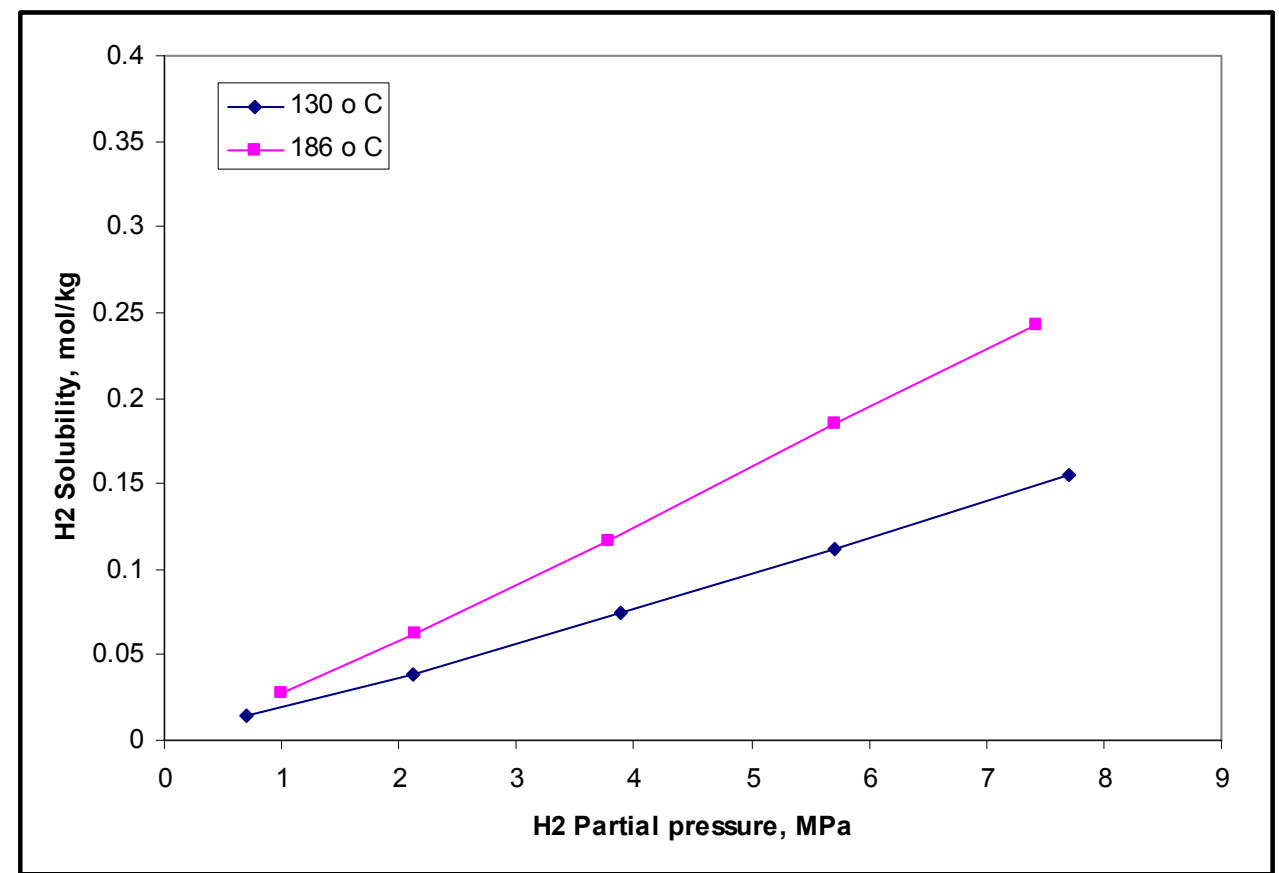

Figure 7: Raw hydrogen solubility data for ABVB

Table 2: Hydrogen solubility coefficients, moles of hydrogen/kg liquid/MPa

\begin{tabular}{|l|c|c|c|c|}
\hline \multirow{2}{*}{} & \multicolumn{4}{|c|}{ Temperature ${ }^{\circ} \mathrm{C}$} \\
\cline { 2 - 5 } & 80 & 130 & 186 & 250 \\
\hline Hexadecane & 0.048 & 0.061 & 0.068 & 0.09 \\
\hline Tetralin & 0.025 & 0.035 & 0.044 & 0.055 \\
\hline ABVB & NA & 0.021 & 0.034 & NA \\
\hline
\end{tabular}




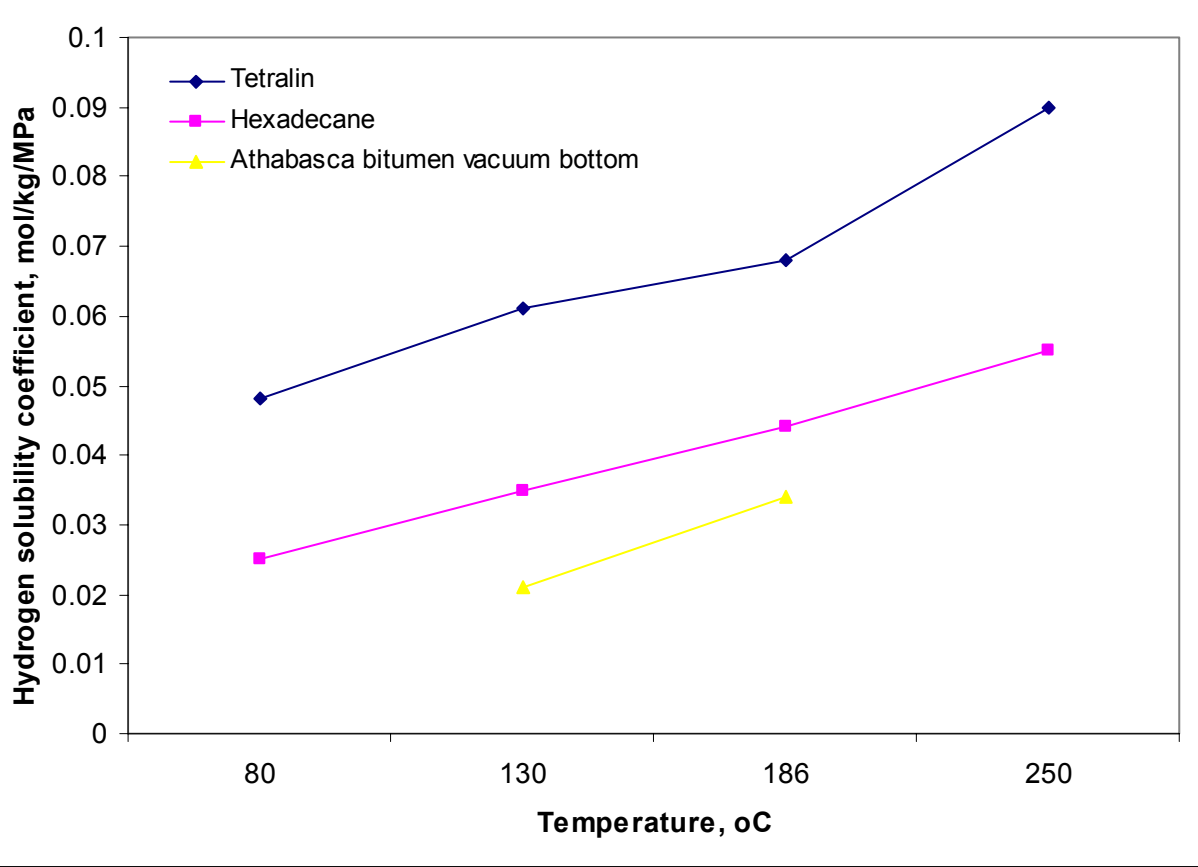

Figure 8: Hydrogen solubility coefficients for tetralin, hexadecane, and ABVB.

\subsubsection{Sorption of hydrogen on solid surfaces in the presence of model liquid hydrocarbon}

Hydrogen sorption rates on activated carbon, even in the absence of solvent, were too low to affect measured hydrogen solubility values for liquids. However, a commercial alumina supported hydrogenation catalyst, did sorb quickly enough to affect apparent solubility measurements within that time frame - Figure 9. For example, after 1 hour at 4.6 $\mathrm{MPa}$, the catalyst sorbed as much hydrogen per $\mathrm{kg}$ as soluble in toluene at the same pressure $\sim 0.15$ moles $/ \mathrm{kg}$. Based on its BET surface area, $280 \mathrm{~m}^{2} / \mathrm{g}$, and assuming that the surface area occupied per sorbed molecule was $15 \times 10^{-20} \mathrm{~m}^{2}$, the ultimate sorbative capacity of the catalyst was $\sim 3.3$ moles of hydrogen $/ \mathrm{kg}$ of catalyst - as long as the pressure is above a threshold value. Therefore, at longer exposure times and at lower total pressures surface sorption can play a dominant role in apparent solubility measurement, even for low molar mass solvents. Since hydrogen solubility in heavy oils is much lower than in toluene at low temperature, excessive apparent solubilities are clearly possible. 


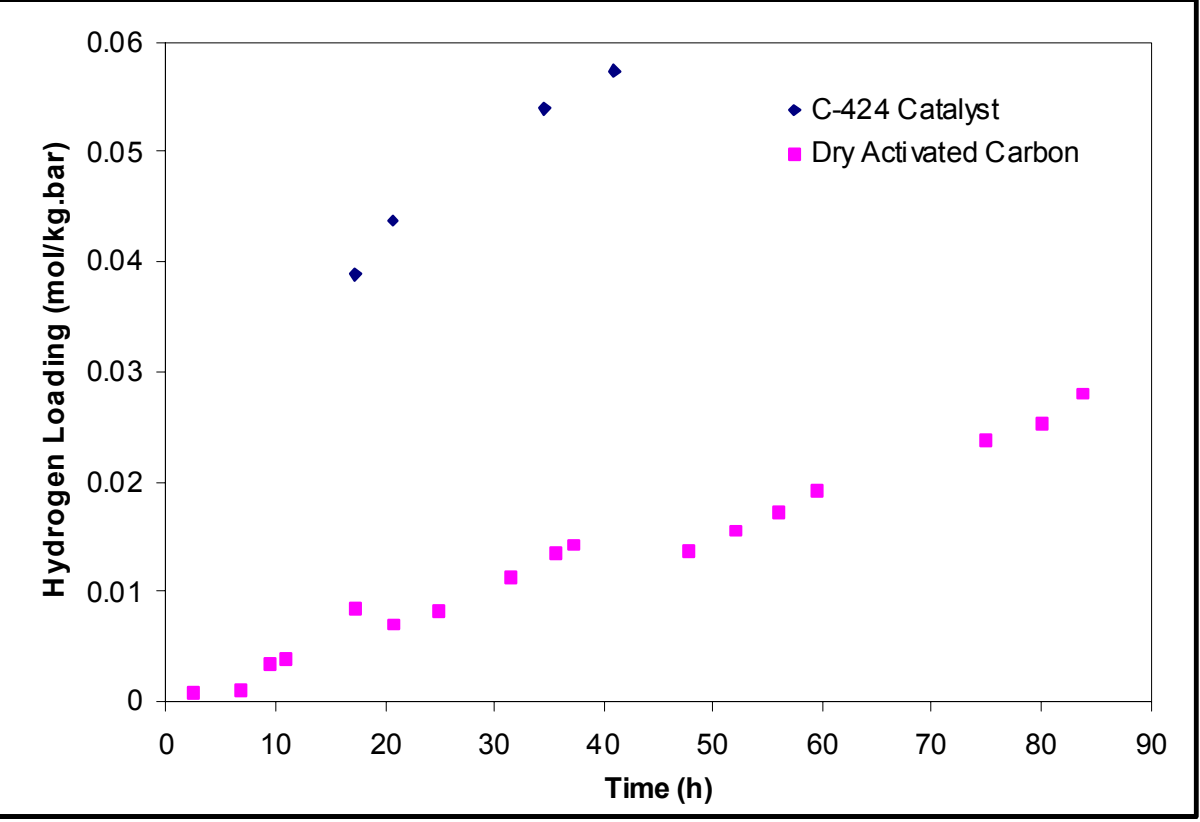

Figure 9: Hydrogen sorption kinetics at room temperature in the absence of solvent at a total pressure of $\sim 4.6 \mathrm{MPa}$, hydrogenation catalyst, and $\sim 6 \mathrm{MPa}$, for the activated carbon.

We obtained apparent hydrogen solubility measurements in tetralin in the presence of an additive. The masses of tetralin and alumina were 99.40 and $49.08 \mathrm{~g}$, respectively. The operating temperatures were 80 and $186^{\circ} \mathrm{C}$. Apparent hydrogen solubility data for tetralin + alumina is shown in Figure 8. The apparent hydrogen solubilities were reported on the basis of liquid mass for ease of comparison with intrinsic hydrogen solubilities in tetralin. As shown in Figure 10 hydrogen does not sorb significantly on alumina surface in the presence of tetralin despite its high sorption capacity for hydrogen in the absence of these model hydrocarbons. In this case liquid suppressed hydrogen sorption on the solids, i.e.: liquid is sorbed preferentially. We are planning a follow-up study to examine the impact of natural clay, asphaltenes, silica, and commercial hydrotreating catalyst on the apparent solubility of hydrogen in hydrocarbon fluids. 


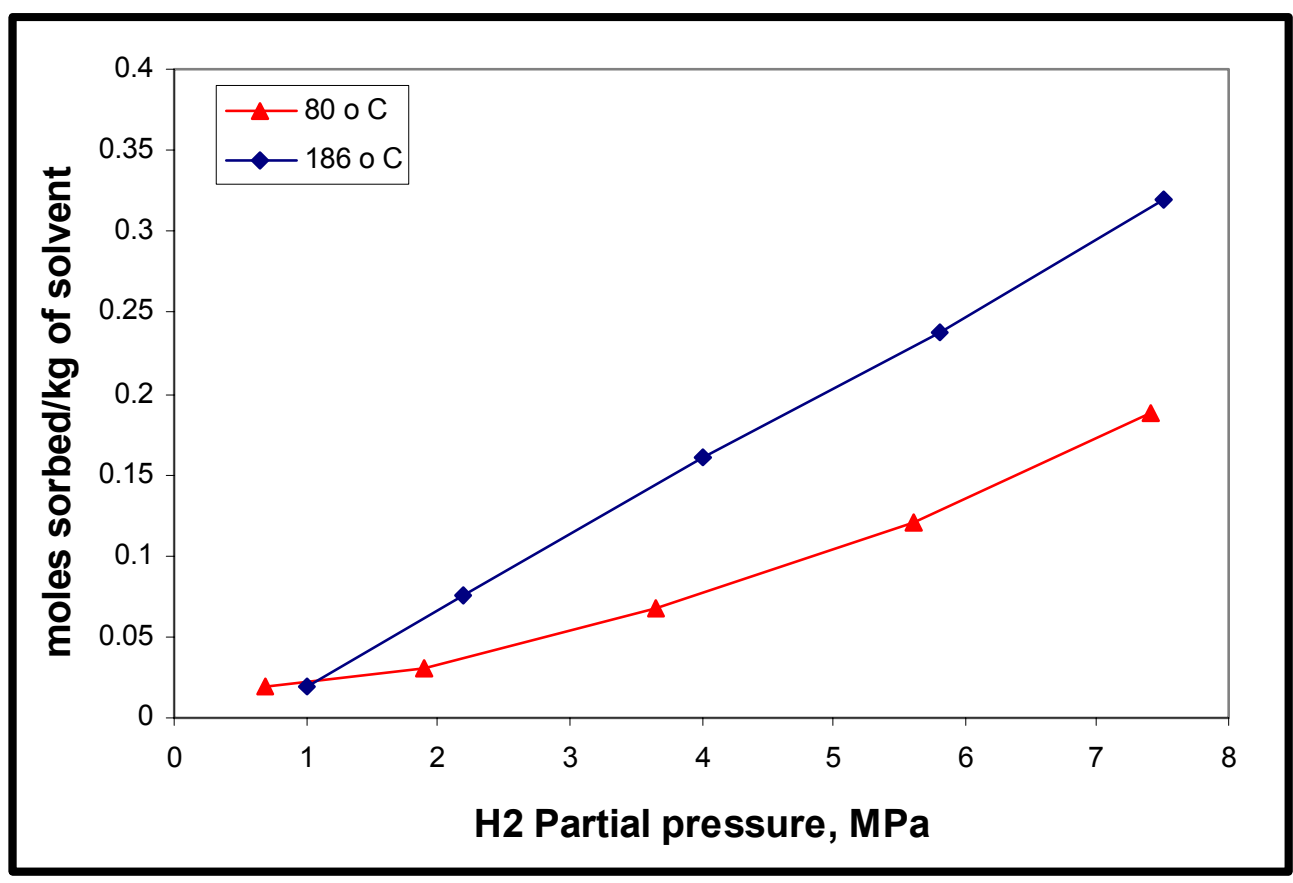

Figure 10: Apparent hydrogen solubilities in tetralin in the presence of alumina.

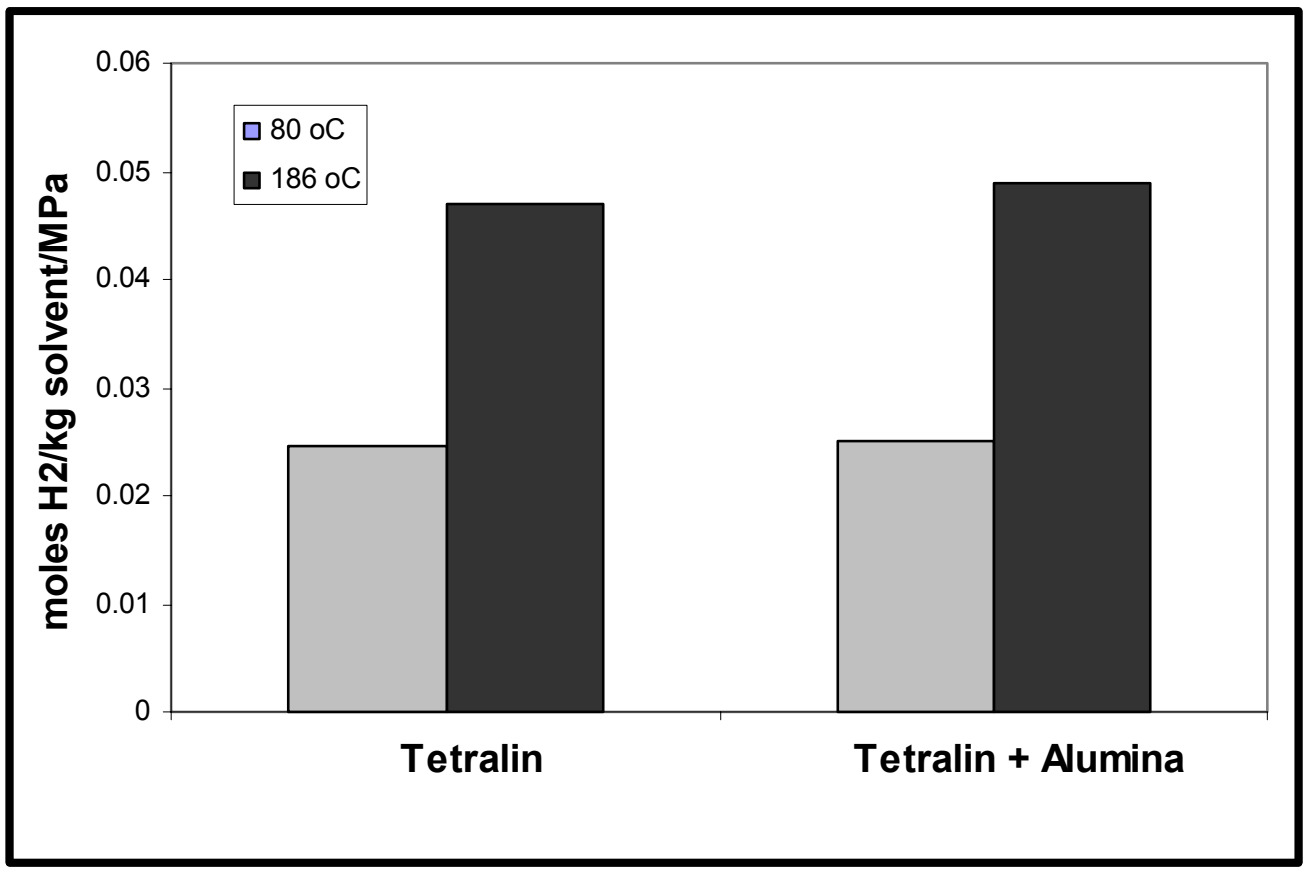

Figure 11: Apparent hydrogen solubility coefficient in tetralin in the presence of Alumina 


\subsection{Training}

In this project Dr. Abedi leveraged in order to train students in a variety of areas, including thermodynamics, reaction kinetic, environmental protection, plant design, optimization, and its applications. I will use the results from this research to enhance a variety of courses offered at Clark Atlanta University. In the undergraduate level Kinetic and Reactor Design (ENGR 363) and Separation Processes (ENGR 483) courses, Dr. Abedi will assign team projects to students involving experimental work. In Instrumentation Methods (ENGR 315), he will assign undergraduate students to carry out the experiments and measurements. In addition, he has offered undergraduate senior projects related to this research. One undergraduate student (Ms. Jenine Breland) completed thesis in this research area. She presented the result of this work in American Chemical Society, which was held in Boston, MA in August 2002. 


\subsection{CONCLUSIONS AND FUTURE WORK}

\subsection{Conclusions}

A non-intrusive and indirect gas solubility measurement method, which argues the capabilities of an existing view cell apparatus, has been implemented successfully. The accuracy of the method was illustrated through hydrogen solubility measurements in hexadecane and tetralin, which were in close agreement with the values available in the literature over a broad range of conditions. Hydrogen solubility in ABVB was measured. ABVB exhibited a sharp increase in hydrogen solubility with temperature. Apparent hydrogen solubility measurements in tetralin in the presence of an additive were obtained. Hydrogen does not sorb significantly on alumina surface in the presence of tetralin despite its high sorption capacity for hydrogen in the absence of these model hydrocarbons.

\section{$5.2 \quad$ Future Work}

As the cell has aged, leaks arise more frequently, and more maintenance is required. We plan to prepare designs for a smaller, less complex and more robust view cell in an effort to establish the view cells as the technique for assessing complex phase behavior of hydrocarbon fluids. The existing cell has proven to be more awkward to handle and maintain and less reliable than anticipated. These improvements will facilitate the experiments and enable us to perform as many experiments as we would like. A broader range of operating conditions will also be accessible. We are now working on view cell specifications and hoping to have a $150 \mathrm{ml}$ volume view cell, with a maximum working

pressure and temperature of $14 \mathrm{MPa}$ and $725 \mathrm{~K}$ respectively. 


\subsection{REFERENCES}

1. Abedi, J., Dukhedin-Lalla, L. and Shaw, J.M., "The Impact of Impregnated Catalysts on Coal Particle Disintegration at Elevated Temperatures and Pressures", Energy and Fuels, 8, 1049-1054 (1994).

2. Wilson, G. M., Johnson, R. H., Hwang, S. C., Tsonopoulos, C., "Volatility of coal liquids at high temperatures and pressures", Ind. Eng. Chem. Process Des. Dev., 20, 94-104 (1981).

3. Palczewska, W., "Catalytic Activity of hydrogen on Pd \& Ni hydride phases", Advances in Catalysis, vol. 24, pp. 245-292 (1975).

4. De Jong, K.P., Reinalda, D., Emeis, C.A., "Coke deposition in trickle-bed reactors during heavy oil processing - catalytic and physical effects, Catalyst deactivation, Delmon, B. \& Froment, G. F., eds., Studies in Surface Science and Catalysis, Elsevier, 88, 155-166 (1994).

5. Shaw, J.M., "A Correlation for Hydrogen Solubility in Alicyclic and Aromatic Hydrocarbon Solvents", Can. J. Chem. Eng ., 65, pp. 293-298 (1987).

6. Chung, K. H., "Hydrogen Adsorption on Catalyst in Bitumen Hydroprocessing", paper presented at the 44th CSChE Conf., Calgary, October (1995).

7. Moyes, R. B., "Reactivity of Hydrogen in Sulfide Catalysts", Hydrogen Effects in Catalysis, vol 31, Chem. Ind., Dekker (1988).

8. Fahim, M.A. and Elkilani, "Prediction of solubility of hydrogen in naphta reformate using the modified UNIFAC group contribution method", A.S., Ind. Eng. Chem. Res., vol 30, pp 255-259 (1991).

9. Lin, M.H., Sebastian, H.M., Simnick, J.j., Chao, K.C., " Solubilities of hydrogen and methane in coal liquids", Ind. Eng. Chem. Process Des. Dev., vol 20, pp 253256 (1981).

10. Simnick, J.J., Lawson, C.C., Lin, H.M., Chao, K.C., "Vapor-liquid equilibrium of hydrogen/tetralin system at elevated temperatures an pressures", AIChE Journal, 23, 4, pp 469-476 (1977).

11. Wainwright, M.S., Ahn, T., Trimm, D.L., Cant, N.W., "Solubility of hydrogen in alcohols and esters", J. Chem. Eng. Data, 32, pp 22-24, (1987).

12. Kim, K.J., Way, T.R., and Feldman Jr., K.T., "Solubility of hydrogen in octane, 1octane, and squalane", J. Chem. Eng. Data, 42, pp 214-215 (1997). 
13. Purwanto, R., Deshpande, R.M., Chaudhari, R.V., Delmas, H.J., "solubility of hydrogen, carbon monoxide, and 1-octane in various solvents and solvent mixtures", J. Chem. Eng. Data, 41, pp 1414-1417 (1996).

14. Ding, F.X., Chiang, S.H., Klinzing, G.E., "Hydrogen solubility in coal liquid", Fuel, 64, pp 1301-1306 (1985).

15. Liaw, S.J., Chiang, S.H., Klinzing, G.E., "hydrogen solubility of hydrogenmethane-tetralin and hydrogen-ethane-tetralin systems at elevated temperatures and pressures", Fuel, 70, pp 771-777 (1991).

16. Froment, G. F., Bischoff, K. B., Chemical Reactor Design and Analysis, 2nd Ed., Wiley, New York, USA, (1990).

17. Gunn, R.D., Chueh, P.L., Prausnitz, J.M., AIChE Journal, 12, pp937-940 (1966).

18. Cai, H.Y., Shaw, J.M., Chung, K.H., "Hydrogen solubility measurements in heavy oil and bitumen cuts", Fuel, 80, pp 1055-1063 (2001).

19. Lin, M.H., Sebastian, H.M., Simnick, J.j., Chao, K.C., "Gas-liquid equilibrium in hydrogen $+\mathrm{n}$-hexadecane and methane $+\mathrm{n}$-hexadecane at elevated temperatures and pressures", J. Chem. Eng. Data, 25, pp 252-254 (1980). 